\title{
Getting Serious About Social Media: Strategies for Increasing Civic Participation
}

\author{
Ben Shneiderman \\ Dept. of Computer Science \& Human-Computer Interaction Lab \\ University of Maryland, College Park, MD, USA \\ ben@cs.umd.edu
}

\begin{abstract}
Technology-mediated social participation is generated when social networking tools (such as Facebook), blogs and microblogs (Twitter), usergenerated content sites (YouTube), discussion groups, problem reporting, recommendation systems, and other social media are applied to national priorities such as health, energy, education, disaster response, environmental protection, business innovation, cultural heritage, or community safety.
\end{abstract}

Fire, earthquake, storm, fraud, or crime reporting sites provide information to civic authorities, AmberAlert has more than 7 million users who help with information on child abductions, Peer-to-Patent provides valuable information for patent examiners, and the SERVE.GOV enables citizens to volunteer for national parks, museums and other institutions. These early attempts hint at the vast potential for technology-mediated social participation, but substantial research is needed to scale up, raise motivation, control malicious attacks, limit misguided rumors, and protect privacy (http://iparticipate. wikispaces.com).

As national initiatives are launched in several countries to dramatically increase research and education on social media, a coordinated approach will be helpful. Clearly stated research challenges should have three key elements: (1) close linkage to compelling national priorities (2) scientific foundation based on established theories and well-defined research questions (privacy, reciprocity, trust, motivation, recognition, etc.), and (3) computer science research challenges (security, privacy protection, scalability, visualization, enduser development, distributed data handling for massive user-generated content, network analysis of community evolution, cross network comparison, etc.).

\section{Potential short-term interventions include:}

- universities changing course content, adding courses, and offering new degree programs
- industry helping researchers by providing access to data and platforms for testing

- government agencies applying these strategies in pilot studies related to national priorities

\section{National Science Foundation Workshops}

Under support from the U.S. National Science Foundation (Jennifer Preece (Principal Investigator), Peter Pirolli (Co-PI), Ben Shneiderman (Co$\mathrm{PI})$ ) workshops were organized in Palo Alto, CA (December 10-11, 2009) and Arlington, VA (April 22$23,2010)$. The focus was on Technology-Mediated Social Participation (www.tmsp.umd.edu) which was intended to encompass civic efforts that would benefit local, regional, national, and international communities. The $60+$ participants included a range of faculty and graduate students from a variety of disciplines, plus representatives of key corporations, government agencies, and non-government organizations. The groups developed six chapters the covered scientific foundations, infrastructure building, design strategies, health/wellness, e-government applications, and educational curriculum recommendations.

\section{Theories and Frameworks}

A central challenge for researchers in technologymediated social participation is to develop theories. These theories could be basic descriptive theories that report on the distinctions among communities and their activities. A second form of theory is explanatory, which deals with cause and effect relationship that might help community managers understand how external or internal event impact activity. The third form of theory is prescriptive, providing guidelines for practice based on experience. The fourth form of theory is predictive, which allows quantitative measures that can be used to predict future activity. 


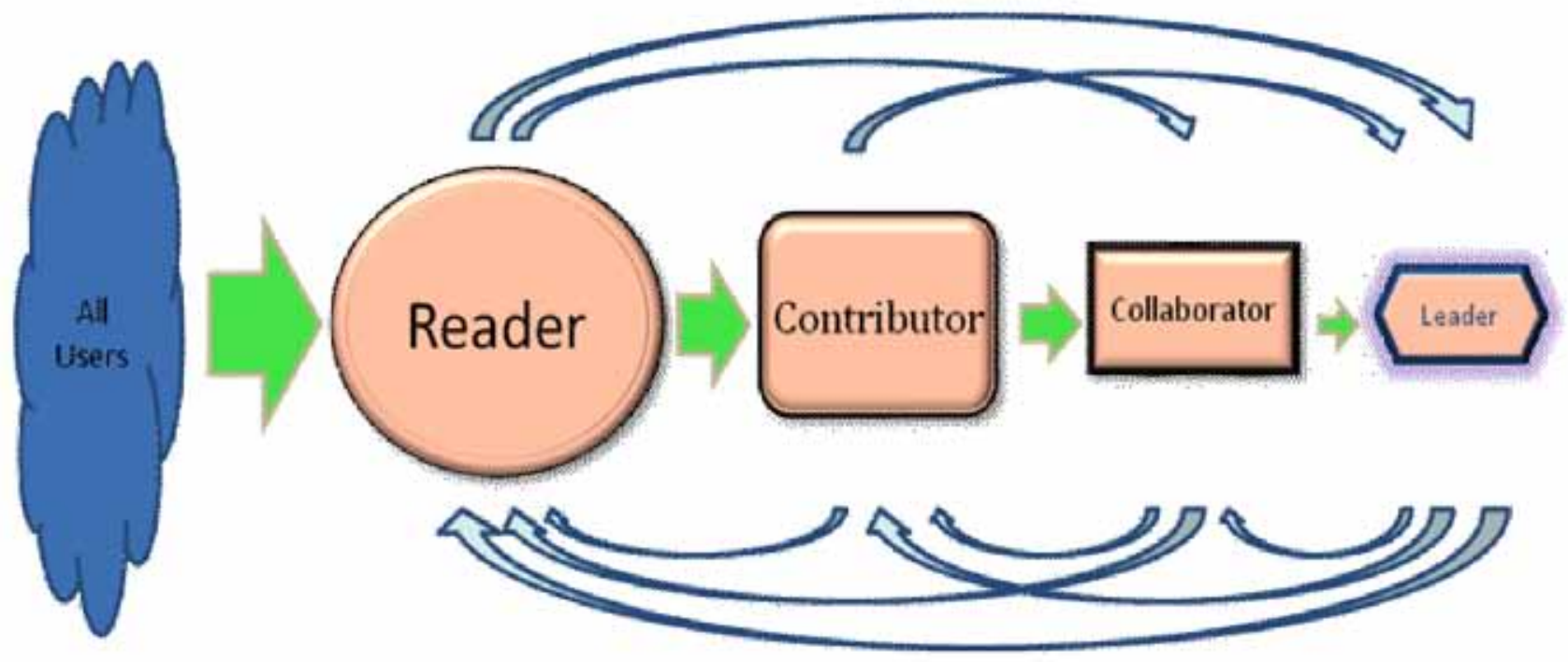

The Reader-to-Leader Framework is an attempt to describe common paths for social media participation. Many users move from being a reader of online content to a contributor of user generated content. They may start with contributing single edits, ratings, photos, videos, or posts, and moving on to contributing more substantive bodies of material. Collaborators work together over periods of weeks or months to make more substantial contributions, and leaders act to set policies, deal with problems, and mentor new users [1].

Tracking the process of contributing and collaborating is becoming a central task to understanding and influencing the development on social participation. Our efforts, supported by Microsoft External Research, have led to development of a free and open-source tool: Network Overview for Discovery and Exploration in Excel (NodeXL) [2]. It enables users to download networks from email, discussion groups, Twitter, Flickr, Youtube, and other sources into Excel 2007/2010 and invoke analytic tools such as metrics, clustering, and filtering. Then users can display the results as a node-link diagram with rich control of visual attributes supported by strong filtering tools.

\section{REFERENCES}

1. Preece, J. and Shneiderman, B., The Readerto-Leader Framework: Motivating technologymediated social participation, AIS Transactions on Human-Computer Interaction 1, 1 (March 2009), 13-32, available at http://aisel.aisnet.org/thci/vol1/ iss $1 / 5 /$

2. Hansen, M., Shneiderman, B, and Smith, M. A., Analyzing Social Media Networks with NodeXL: Insights from a Connected World, Morgan Kaufmann Publishers (2010). 